\title{
Research on Teacher Workload Control Strategy Based on Conductive Knowledge Mining
}

\author{
Ye Guangzi $^{1}$, Chen Yuqiang ${ }^{1}$ and Li Weihua ${ }^{2}$ \\ ${ }^{I}$ Department of Computer Engineering, Dongguan Polytechnic, Dongguan, \\ Guangdong Province 523808) \\ ${ }^{2}$ School of Computer Science and Technology, Guangdong University of \\ Technology, Guangzhou, Guangdong 510006) \\ 375160657@qq.com
}

\begin{abstract}
With the extension data mining technology, the conductive knowledge mining method is applied into the management of college teachers' workload. Under the active transformation of control strategy, the conductive effect and its confidence of teachers' workload are calculated, to obtain the conductivity and the conductivity interval, and mine the conductive knowledge of quantitative or qualitative change. A case study of a college shows that the conductive knowledge with a higher support and confidence is helpful for the management departments of colleges to understand the degree of positive or negative effects of some strategies on teachers' research and teaching workload in quantity, so that they can find an appropriate strategy used to control the teachers' workload.
\end{abstract}

Keywords: Data mining; Extension transformation; Conductive knowledge; Research workload

\section{Introduction}

The scientific research is an important evaluation indicator of the comprehensive strength of a college or university and a key basis for realizing the combination of "production, study and research" as well as the technology transfer. In order to motivate teachers to invest more energy in research, the college management often develops relevant strategies to enhance the research capability of the college. The data information obtained after implementing the research control strategy, can only support simple information inquiry and statistical work through existing Excel or the research information management system [1-2]. It can only indicate whether the strategy is feasible, but is impossible to further understand the degree of positive and negative effects of the strategy on teachers' research and teaching workload in quantity.

Extension data mining put forward in 2004, after 10 years of research and exploration, has gradually defined its research object and target, and initially formed a set of basic theories and methods of mining extension knowledge. However, there is little applied study on conductive knowledge mining. This paper introduces the conductive knowledge mining method [3] of the extension data mining [4-5] and analyzes the conductive effects of teachers' workload, and discovers the conductive knowledge [6-7] such as conductive object, change of conduction feature value, conductivity and extension classification in terms of teachers' workload under the influence of active transformation [8] of the research control strategy. The purpose of this paper is to provide data reference in "quantity" for research managers to analyze the existing data, so that they can propose appropriate strategies to promote the enhancement of scientific research ability of colleges and universities. 


\section{Related Conceptions of Extension Data Mining}

\subsection{Conductive Effects and Conductivity}

The information element set [9]

$$
\left\{I_{i j}(t)\right\}=\left\{\left(O_{i}(t), \quad c_{j}, \quad v_{i j}(t)\right), i=1,2, \cdots, n_{j} j=1,2, \cdots, m\right\}
$$

and a certain information element [10] at $t_{0}$ are given respectively as the above and below.

$$
I_{i_{0} j_{0}}\left(t_{0}\right)=\left(O_{i_{0}}\left(t_{0}\right), \quad c_{j_{0}}, \quad v_{i_{0} j_{0}}\left(t_{0}\right)\right)
$$

If change $\varphi$ realize:

$$
\varphi I_{i_{0} j_{0}}\left(t_{0}\right)=\left(O_{i_{0}}(t), \quad c_{j_{0}}, \quad v_{i_{0} j_{0}}(t)\right)=I_{i_{0} j_{0}}(t)
$$

and when $t>t_{0}, v_{i_{0} j_{0}}(t)=a \neq v_{i_{0} j_{0}}\left(t_{0}\right)$, the value of $v_{i_{0} j_{0}}(t)$ after conducting transformation $\varphi$ will not change with $t$. The conduction transformation $I_{I_{\mathbb{L}_{0} j_{0}}} T_{I_{i j}\left(t_{0}\right)}$ of $\varphi$ relative to $\left\{I_{i j}(t)\right\}$ makes:

$$
I_{i_{0} j_{0}} T_{I_{i j}\left(t_{0}\right)} I_{i j}\left(t_{0}\right)=I_{i j}(t)=\left(O_{i}(t), \quad c_{j}, \quad v_{i j}(t)\right)
$$

when $t>t_{0}$, the conductive effect [11] of transformation $\varphi$ relative to the information element $I_{i j}(t)$ will be:

And the conductivity [3] will be:

$$
\Delta v_{i j}=v_{i j}-v_{i j}\left(t_{0}\right)
$$

$$
\gamma_{i j}(t)=\frac{\Delta v_{i j}}{\left|\alpha-v_{i} j_{0}\left(t_{0}\right)\right|}
$$

\subsection{Conductive Information Element Set and Conduction Interval}

If $\gamma_{i j}(t)=0 \quad, \quad$ namely the conductive effect $v_{i j}(t)-v_{i j}\left(t_{0}\right)=0, i \in\{1,2, \cdots, n\}_{j} j \in\{1,2, \ldots, m\} ; t>t_{0}$, then $I_{i j}$ is the non-conductive information element of $\varphi$, and they are wholly expressed as $I_{\bar{\varphi}}\left(I_{i j}\right)$.

Suppose

$$
I_{\varphi} I_{i j}=\left\{I_{i j}(t)\right\}-I_{\bar{\varphi}}\left(I_{i j}\right)-\left\{I_{i_{0} j_{0}}\left(t_{0}\right)\right\}
$$

is the conductive information element set [Error! Bookmark not defined.][6] of $\varphi$ relative to $\left\{I_{i j}(t)\right\}$.

And take

$$
\gamma_{j \min }=\min _{1 \leq i \leq n} \gamma_{i j}\left(t_{p}\right), \quad \gamma_{j \max }=\max _{1 \leq i \leq n} \gamma_{i j}\left(t_{p}\right)
$$

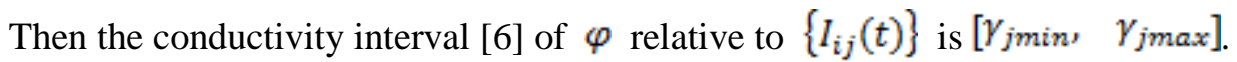

\subsection{Number of Samples and Confidence}

If the information element $I_{i j}(t)$ meets the condition of $L: v_{i 7} \in V_{j}$, then:

$$
\left(\varphi I_{i_{0} j_{0}}\left(t_{0}\right)=I_{i_{0} j_{0}}(t)\right) \wedge\left(I_{i j} \ni L\right) \Rightarrow(\ell)\left\{\gamma_{i j} \in\left[\gamma_{j \min }, \gamma_{j \max }\right]\right\}
$$

Where,

$$
\ell=(\text { samples, confidence })=\left(n q, \frac{\left.\mid\left[L_{i j}\left(t_{p}\right)\right\}\right]}{n q}\right)
$$


$\left|\left\{I_{i j}\left(t_{p}\right)\right\}\right|$ is the number of information elements meeting the condition

$$
\left|v_{i j}(t)-v_{i j}\left(t_{0}\right)\right|>\delta, \quad p=1,2, \cdots, q
$$

In the information element set $\left\{I_{i j}(t)\right\}, n q$ is the number of information elements in the data sheet, and $\delta$ is the threshold value [12] relative to the feature $c_{j}$

\subsection{Simple Correlation Function}

Set the value range of $x$ is the finite interval $\langle a, b]$, the positive region is $X=\left\langle a_{1}, b\right], a_{1} \geq a$ and the optimal point is $b$. Then establish a simple correlation function [13]:

$$
k(x)=\frac{x-a_{1}}{b-a}
$$

Suppose

$$
\alpha_{i}=k\left(u_{i}^{r}\right)-k\left(u_{i}\right)
$$

is the correlation difference [6] of information element $I_{i}$ relative to the evaluation feature $d$ under the transformation $\varphi$;

Suppose

$$
\beta_{i}=k\left(u_{i}^{r}\right) \cdot k\left(u_{i}\right)
$$

is the correlation product [6] of information element $I_{\bar{i}}$ relative to the evaluation feature $d$ under the transformation $\varphi$;

\section{The Basic Methods of Conductive Knowledge Mining}

There are usually three ways to get knowledge related to the conduction transformation from the database:

(1) Get mining conductive knowledge from multiple characteristics value of one object;

(2) Get mining conductive knowledge from the same characteristics value of multiple objects;

(3) Get mining conductive knowledge from multiple characteristics value of multiple objects.

The general steps of conductive knowledge mining are as follows:

(1) Make data preprocessing in the raw database; the primitive is introduced as expression of relevant information; and form "basic information element base before and after transformation" according to the active extension transformation; 


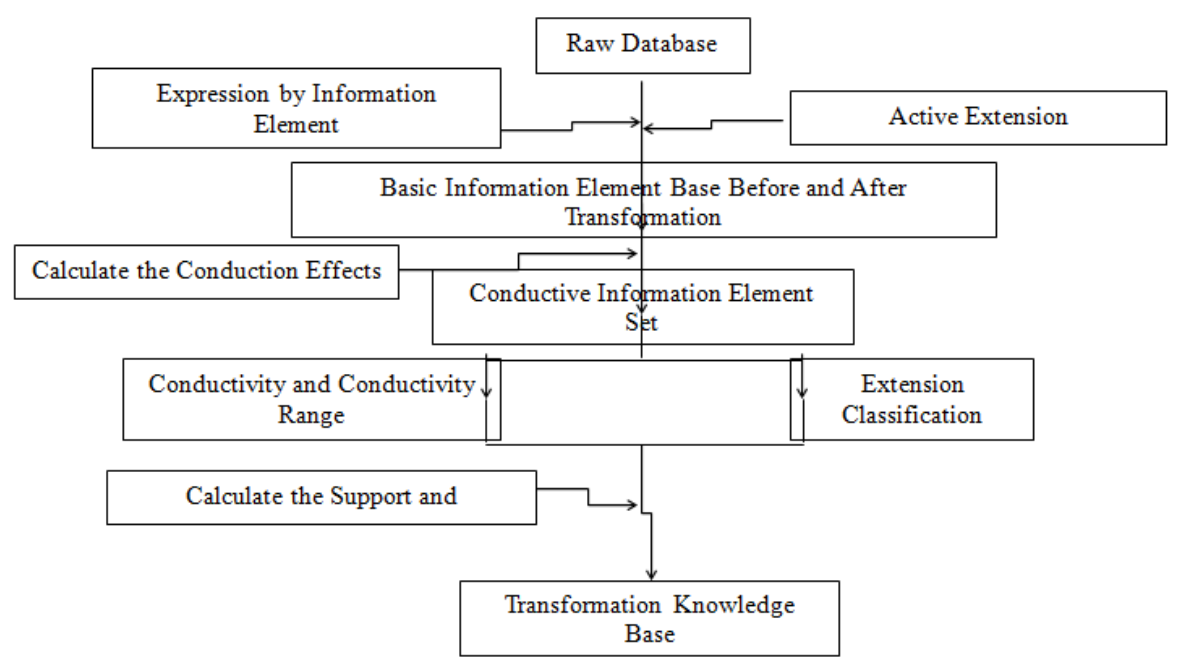

Figure 1. The Basic Methods of Conductive Knowledge Mining

(2) Calculate the conduction effects of the information element in the " basic information element base before and after transformation"; eliminate the object characteristic that the conduction effect should be small or zero; and conductive information element set;

(3) Make conductivity calculation for conductive information element to obtain the transformation about information element's conductivity and conductivity range, and then backtrack and extract the conduction characteristics set and the value range knowledge of conduction characteristics;

(4) Establish correlation function and calculate the relational degree of evaluating characteristic of conductive information element before and after the transmission; combined with correlation difference and correlation product and associated product, mine the extension classification knowledge of conduction information element.

\section{Conductive Knowledge Mining of Research Control Strategy}

To improve teachers' research level, a college developed the research control strategy in 2013 as below: convert the research achievements into "scores" according to their quantity and quality. The score of each research achievement should be accumulated, and count the research workload of teachers once a year. Based on such statistic results, the ones who have reached the workload standard, will be rewarded for the part exceeding such standard as per the rule of $10 \mathrm{RMB}$ for each exceeding score; and the ones who have not reached the workload standard, will be subject to the deduction of incentive allowances as per the rule of $10 \mathrm{RMB}$ for each unreached score accordingly. The teachers' workload mainly includes teaching workload and research workload. What conductive effect will be produced for these two types of workloads under the action of research control strategies? Next, let's analyze it with the extension conductive knowledge mining method.

\subsection{Data Acquisition and Pre-processing}

In this case, the data of research workload and teaching workload of teachers in Department of Computer Engineering provided by the Research Office and the Office of Academic Affairs of this university is used as the object of study. The data has been pre-processed, and as the result, the records of teachers whose data is default or does not exist from 2012 to 2015, have been removed. Thus, a table containing teachers' basic information elements before and after the introduction of research control strategy is obtained, as shown in Table 1. 
Table 1. Teachers' Basic Information Elements Table from 2012 to 2015

\begin{tabular}{|c|c|c|c|c|c|c|}
\hline $\begin{array}{l}\text { Feature } \\
\text { Teacher } \\
\text { Name }\end{array}$ & $\begin{array}{c}\text { Teacher } \\
\text { Number } \\
c_{1}\end{array}$ & $\begin{array}{c}\text { Gender } \\
c_{2}\end{array}$ & $\begin{array}{c}\text { Education } \\
\text { Background } \\
c_{3}\end{array}$ & $\cdots$ & $\begin{array}{c}\text { Research } \\
\text { Workload } \\
\text { (scores) } \\
c_{7} \\
\end{array}$ & $\begin{array}{c}\text { Teaching } \\
\text { Workload } \\
\text { (class hour) } \\
c_{8}\end{array}$ \\
\hline$o_{1}\left(t_{0}\right)$ & 2009036 & male & postgraduate & $\ldots$ & 1560 & 568 \\
\hline$O_{2}\left(t_{0}\right)$ & 2009037 & female & undergraduate & $\ldots$ & 100 & 786 \\
\hline$\vdots$ & $\vdots$ & $\vdots$ & $\vdots$ & $\vdots$ & $\vdots$ & $\vdots$ \\
\hline$O_{24}\left(t_{0}\right)$ & 2012066 & female & undergraduate & $\ldots$ & 128 & 702 \\
\hline$O_{1}\left(t_{1}\right)$ & 2009036 & male & postgraduate & $\ldots$ & 6641 & 678 \\
\hline$o_{2}\left(t_{1}\right)$ & 2009037 & female & undergraduate & $\ldots$ & 1039 & 724 \\
\hline$\vdots$ & $\vdots$ & $\vdots$ & $\vdots$ & $\vdots$ & $\vdots$ & $\vdots$ \\
\hline$O_{a 4}\left(t_{1}\right)$ & 2012066 & female & undergraduate & $\ldots$ & 660 & 889 \\
\hline$O_{1}\left(t_{2}\right)$ & 2009036 & male & postgraduate & $\ldots$ & 8195 & 545 \\
\hline$O_{2}\left(t_{2}\right)$ & 2009037 & female & undergraduate & $\ldots$ & 600 & 748 \\
\hline$\vdots$ & $\vdots$ & $\vdots$ & $\vdots$ & $\vdots$ & $\vdots$ & $\vdots$ \\
\hline$O_{a 4}\left(t_{2}\right)$ & 2012066 & female & undergraduate & $\ldots$ & 924 & 728 \\
\hline$O_{1}\left(t_{a}\right)$ & 2009036 & male & postgraduate & $\ldots$ & 6879 & 437 \\
\hline$O_{2}\left(t_{a}\right)$ & 2009037 & female & undergraduate & $\ldots$ & 3326 & 633 \\
\hline$\vdots$ & $\vdots$ & $\vdots$ & $\vdots$ & $\vdots$ & $\vdots$ & $\vdots$ \\
\hline$O_{34}\left(t_{a}\right)$ & 2012066 & female & undergraduate & $\ldots$ & 2823 & 659 \\
\hline
\end{tabular}

\subsection{Expression of Data Information Element}

In this case, suppose $t_{0}=2012, t_{1}=2013, t_{2}=2014$ and $t_{3}=2015$. Due to the introduction of the research control strategy, the active transformation $\varphi$ occurs in the information element $I_{0}\left(t_{0}\right)$, so $\varphi I_{0}\left(t_{0}\right)=I_{0}\left(t_{p}\right)$, then:

$I_{0}\left(t_{0}\right)=\left(O_{0}\left(t_{0}\right), c, v\left(t_{0}\right)\right)=\left(\right.$ research work $O\left(t_{0}\right)$, score, $0 \mathrm{RMB} /$ score $)$,

$I_{0}\left(t_{p}\right)=\left(O_{0}\left(t_{p}\right), c, v\left(t_{p}\right)\right)=\left(\right.$ research work $O\left(t_{p}\right)$, score, $10 \mathrm{RMB} /$ score $)$,

$p \in\{1,2,3]$, and the value of $v\left(t_{p}\right)$ in the three years after the active transformation is not changed.

Under the influence of the above active transformation $\varphi$, the change in the information element $I_{i j}(t)$ belongs to conduction transformation, expressed as

$$
{ }_{I_{0}} T_{I_{i j}} I_{i j}\left(t_{0}\right)=I_{i j}\left(t_{p}\right), i \in\{1,2, \cdots, 34\}, j \in\{1,2, \cdots, 8\}, p \in\{1,2,3\} .
$$

\subsection{Calculation of Conductive Effect to Acquire the Conductive Information Element Set}

In order to mine the conductive knowledge of research control strategy of teachers' workload, calculate the conductive effect of information element $I_{i j}(t)$, to determine the conductive information element set and the non-conductive information element set according to the effect. Based on Formula (1):

$$
\Delta v_{i j}=v_{i j}\left(t_{p}\right)-v_{i j}\left(t_{0}\right), \quad i \in\{1,2, \cdots, 34\}, j \in\{1,2, \cdots, 8\}, p \in\{1,2,3\}
$$


calculate the difference between information element values in Table 1 before and after the transformation is conducted. The result is shown in Table 2.

Table 2. Difference between Information Element Values before and after the Transformation

\begin{tabular}{|c|c|c|c|c|c|c|}
\hline $\begin{array}{l}\text { Feature } \\
\text { Teacher } \\
\text { Name }\end{array}$ & $\begin{array}{c}\text { Teacher } \\
\text { Number } \\
c_{1}\end{array}$ & $\begin{array}{c}\text { Gender } \\
c_{2}\end{array}$ & $\begin{array}{c}\text { Education } \\
\text { Background } \\
c_{3}\end{array}$ & $\cdots$ & $\begin{array}{c}\text { Research } \\
\text { Workload } \\
\text { (scores) } \\
c_{7} \\
\end{array}$ & $\begin{array}{c}\text { Teaching } \\
\text { Workload } \\
\text { (class hour) } \\
c_{8} \\
\end{array}$ \\
\hline$O_{1}\left(t_{1}\right)$ & 0 & 0 & 0 & $\ldots$ & 5081 & 110 \\
\hline$O_{2}\left(t_{1}\right)$ & 0 & 0 & 0 & $\ldots$ & 939 & -62 \\
\hline$\vdots$ & $\vdots$ & $\vdots$ & $\vdots$ & $\vdots$ & $\vdots$ & $\vdots$ \\
\hline$O_{24}\left(t_{1}\right)$ & 0 & 0 & 0 & $\ldots$ & 532 & 187 \\
\hline$O_{1}\left(t_{2}\right)$ & 0 & 0 & 0 & $\ldots$ & 6635 & -23 \\
\hline$O_{2}\left(t_{2}\right)$ & 0 & 0 & 0 & $\ldots$ & 500 & -38 \\
\hline$\vdots$ & $\vdots$ & $\vdots$ & $\vdots$ & $\vdots$ & $\vdots$ & $\vdots$ \\
\hline$O_{24}\left(t_{2}\right)$ & 0 & 0 & 0 & $\ldots$ & 796 & 25 \\
\hline$O_{1}\left(t_{a}\right)$ & 0 & 0 & 0 & $\ldots$ & 5319 & -131 \\
\hline$O_{2}\left(t_{a}\right)$ & 0 & 0 & 0 & $\ldots$ & 3226 & -153 \\
\hline$\vdots$ & $\vdots$ & $\vdots$ & $\vdots$ & $\vdots$ & $\vdots$ & $\vdots$ \\
\hline$O_{24}\left(t_{a}\right)$ & 0 & 0 & 0 & $\ldots$ & 2695 & -43 \\
\hline
\end{tabular}

According to the data analysis in Table 2, the research workload score was enhanced from $0 \mathrm{RMB} /$ score to $10 \mathrm{RMB} / \mathrm{score}$, while the teaching number, gender, education background and other features are not affected. However, the teachers' research workload and teaching workload were affected a lot by the conduction. According to Formula (3), the non-conductive information element set and the conductive information element set can be obtained as:

$$
\begin{gathered}
I_{\bar{\varphi}} I_{i j}=\left\{\left(O_{i}, \quad c_{j}, v_{i j}\right) ; i=1,2, \cdots, 34 ; j=1,2, \cdots, 6\right\} \\
I_{\varphi} I_{i j}=\left\{\left(O_{i}, c_{7,}, v_{i 7}\right),\left(O_{i}, \quad c_{8}, \quad v_{i 8}\right) ; i=1,2, \cdots, 34\right\}
\end{gathered}
$$

\subsection{Extract the Knowledge of Transformation about the Conductivity of Information Elements}

After the conductive information element set is obtained, the conductivity of transformation $\varphi$ for the information element $I_{i j}$ may be calculated through Formula (2), to understand the degree of the influence of research control strategy on teachers' workload. As the research workload score was enhanced from $0 \mathrm{RMB} / \mathrm{score}$ to 10 $\mathrm{RMB} /$ score after the active transformation was conducted, and kept unchanged for 3 years, then $a=10, v_{i_{0} j_{0}}\left(t_{0}\right)=0$. Substitute it into Formula (2), and we obtain:

$$
\gamma_{i j}\left(t_{p}\right)=\frac{v_{i j}\left(t_{p}\right)-v_{i j}\left(t_{0}\right)}{\left|a-v_{i_{0} j_{0}}\left(t_{0}\right)\right|}=\frac{v_{i j}\left(t_{p}\right)-v_{i j}\left(t_{0}\right)}{|10-0|}, i \in\{1,2, \cdots, 34\}, j \in\{7,8\}, \quad p \in\{1,2,3\}
$$

Calculate the conductivity and conduction interval of the research workload $c_{7}$ and the teaching workload $c_{8}$ of conduction feature according to Table 2, as shown in Table 3. 


\section{Table 3. Conductivity of Conductive Information Element after Transformation}

\begin{tabular}{|c|c|c|}
\hline $\begin{array}{l}\text { Feature } \\
\text { Teacher } \\
\text { Name }\end{array}$ & $\begin{array}{c}\text { Research } \\
\text { Workload } \\
\text { (scores) } \\
c_{7} \\
\end{array}$ & $\begin{array}{c}\text { Teaching } \\
\text { Workload } \\
\text { (class hour) } \\
c_{8} \\
\end{array}$ \\
\hline$O_{1}\left(t_{1}\right)$ & 508 & 11 \\
\hline$O_{2}\left(t_{1}\right)$ & 940 & -6 \\
\hline$\vdots$ & $\vdots$ & $\vdots$ \\
\hline$O_{24}\left(t_{1}\right)$ & 53 & 19 \\
\hline$O_{1}\left(t_{2}\right)$ & 664 & -2 \\
\hline$O_{2}\left(t_{2}\right)$ & 50 & -4 \\
\hline$\vdots$ & $\vdots$ & $\vdots$ \\
\hline$O_{a 4}\left(t_{2}\right)$ & 80 & 3 \\
\hline$O_{1}\left(t_{a}\right)$ & 532 & -13 \\
\hline$O_{2}\left(t_{a}\right)$ & 323 & -15 \\
\hline$\vdots$ & $\vdots$ & $\vdots$ \\
\hline$O_{34}\left(t_{a}\right)$ & 2670 & -4 \\
\hline $\min _{\substack{1 \leq 1 \leq n \\
1 \leq p \leq q}} \gamma_{i j}\left(t_{p}\right)$ & -286 & -58 \\
\hline $\max _{\substack{1 \leq i \leq n \\
1 s p s q}} \gamma_{i j}\left(t_{p}\right)$ & 664 & 34 \\
\hline $\begin{array}{l}\text { conduction } \\
\text { interval }\end{array}$ & {$[-286,664]$} & {$[-58,34]$} \\
\hline
\end{tabular}

According to Tables 1 and 3, substitute them into Formulas (5), (6) and (7), and the following two items of knowledge can be obtained:

(1) If the information element $I_{i 7}=\left(\begin{array}{llll}O_{i}, & c_{7}, & v_{i 7}\end{array}\right)$ meets the condition $L: v_{i 7} \in[0,8728]$, then:

$\left[\varphi\right.$ (Research workload $O\left(t_{0}\right)$,score, 0 score/month $)$

$$
\begin{aligned}
& \left.=\left(\text { Research workload } O\left(t_{0}\right), \text { score, } 10 \text { scrores } / \text { month }\right)\right] \\
& \wedge\left(I_{i 7} \ni L\right) \Rightarrow\left(\ell_{7}\right)\left(\gamma_{i 7} \in[-286,664]\right)
\end{aligned}
$$

Where, $\ell_{7}=\left(n q, \frac{\| x_{i, 7\}} \mid}{n q}\right)=\left(102, \frac{97}{102}\right)$, and the threshold value $\delta_{7}=50$.

This knowledge indicates that when the research workload score is increased to 10 scores/month, if teachers' research workload belonging to $[0,8728]$, the conduction interval will be $[-286,664]$, the number of samples is 102 and the confidence is $97 / 102$, where 97 is the number of information element $\left|v_{i 7}\left(t_{p}\right)-v_{i 7}\left(t_{0}\right)\right| \geq 50$ in Table 2. That means, the confident level that the teachers' research workload has conduction transformation is $95.10 \%$.

(2). If the information element $I_{i 8}=\left(O_{i}, c_{8}, v_{i 8}\right)$ meets the condition $L: v_{i 8} \in[60,1015]$, then:

$$
\begin{gathered}
{\left[\varphi\left(\text { Research workload } O\left(t_{0}\right), \text { score, } 0 \text { score } / \text { month }\right)\right.} \\
\left.=\left(\text { Research workload } O\left(t_{0}\right), \text { score, } 10 \text { scrores } / \text { month }\right)\right] \\
\wedge\left(I_{i 8} \ni L\right) \Rightarrow\left(\ell_{8}\right)\left(\gamma_{i 8} \in[-58,34]\right)
\end{gathered}
$$


Where, $\ell_{8}=\left(n q, \frac{\|\left[\int_{i 8}\right] \mid}{n q}\right)=\left(102, \frac{98}{102}\right)$, and the threshold value $\delta_{7}=10$.

This knowledge indicates that when the research workload score is increased to 10 scores/month, if teachers' teaching workload belonging to [60,1015], the conduction interval will be $[-58,34]$, the number of samples is 102 and the confidence is 98/102, where 98 is the number of information element $\left|v_{i 8}\left(t_{p}\right)-v_{i 8}\left(t_{0}\right)\right| \geq 10$ in Table 2. That means, the confident level that the teachers' teaching workload has conduction transformation is $95.10 \%$.

\subsection{Extension Knowledge Classification of Mining Conductive Information Elements}

To further determine which type the change of the conductive information element belongs to, we can calculate the degree of correlations before and after the conduction transformation, to obtain the extension knowledge classification under quantitative change or quality change [14-15].

\subsubsection{Calculate the Degree of Correlation of Conductive Information Elements}

According to Table 1, calculate the degree of correlation by respectively taking the research workload $c_{7}$ and the teaching workload $c_{8}$ as the evaluation features of conductive information elements and selecting the simple correlation function with the optimal point on the right.

The value range of teachers' research workload $v_{i 7}$ before and after the transformation is $[0,8728]$, and the basic research workload is 120 . Substitute it into Formula (8), and we obtain:

$$
k\left(v_{i 7}\right)=\frac{v_{i 7}-a_{1}}{b-a}=\frac{v_{i 7}-120}{8728-0}
$$

The value range of teachers' teaching workload $v_{i s}$ before and after the transformation is $[60,1015]$, and the basic research workload is 320 . Substitute it into Formula (8), and we obtain:

$$
k\left(v_{i 8}\right)=\frac{v_{i 8}-a_{1}}{b-a}=\frac{v_{i 8}-320}{1015-60}
$$

Thus, the degree of the correlation of information element may be obtained, as shown in Table 4. 
Table 4. Correlation Degree of Conductive Information Element before and after the Transformation

\begin{tabular}{c|cc}
\hline Neacher & $\begin{array}{c}\text { Research } \\
\text { Workload } \\
\text { (scores) } \\
\boldsymbol{c}_{7}\end{array}$ & $\begin{array}{c}\text { Teaching } \\
\text { Workload } \\
\text { (class hour) } \\
\boldsymbol{c}_{\mathbf{8}}\end{array}$ \\
\hline$O_{1}\left(t_{0}\right)$ & 0.1650 & 0.2599 \\
$O_{2}\left(t_{0}\right)$ & -0.0023 & 0.4879 \\
$\vdots$ & $\vdots$ & $\vdots$ \\
$O_{24}\left(t_{0}\right)$ & 0.0009 & 0.4002 \\
\hline$O_{1}\left(t_{1}\right)$ & 0.7471 & 0.3748 \\
$O_{2}\left(t_{1}\right)$ & 0.1052 & 0.4232 \\
$\vdots$ & $\vdots$ & $\vdots$ \\
$O_{24}\left(t_{1}\right)$ & 0.0619 & 0.5955 \\
\hline$O_{1}\left(t_{2}\right)$ & 0.9252 & 0.2356 \\
$O_{2}\left(t_{2}\right)$ & 0.0550 & 0.4479 \\
$\vdots$ & $\vdots$ & $\vdots$ \\
$O_{24}\left(t_{2}\right)$ & 0.0921 & 0.4268 \\
\hline$O_{1}\left(t_{a}\right)$ & 0.7744 & 0.1229 \\
$O_{2}\left(t_{a}\right)$ & 0.3673 & 0.3280 \\
$\vdots$ & $\vdots$ & $\vdots$ \\
$O_{24}\left(t_{a}\right)$ & 0.3097 & 0.3550 \\
\hline
\end{tabular}

\subsubsection{Analysis of the Extension Classification of Conductive Information Elements}

According to the degree of correlation of the two evaluation features in Table 4, calculate the correlation difference and the correlation product according to Formula (9) and Formula (10) to analyze the extension classification of each conductive information element.

The correlation difference is:

$$
\alpha\left(v_{i j}\right)=k\left(v_{i j}\left(t_{p}\right)\right)-k\left(v_{i j}\left(t_{0}\right)\right)
$$

And the correlation product is:

$$
\beta\left(v_{i j}\right)=k\left(v_{i j}\left(t_{p}\right)\right) * k\left(v_{i j}\left(t_{0}\right)\right)
$$

Where, $i \in\{1,2, \cdots, 34\}, j \in\{7,8\}, p \in\{1,2,3\}$. The extension classification of the conductive information elements were classify according to the classification standard ${ }^{[\text {Error! Bookmark not defined.] }}$ of evaluating information elements, as shown in Table 5 and Table 6. 
Table 5. Extension Classification of Conductive Information Elements in Terms of Research Workload $c_{7}$

\begin{tabular}{|c|c|c|c|c|}
\hline & $\boldsymbol{k}\left(v_{i 7}\right)$ & $\alpha\left(v_{i 7}\right)$ & $\beta\left(v_{i 7}\right)$ & Extension Classification \\
\hline$O_{1}\left(t_{0}\right)$ & $>0$ & & & \\
\hline$O_{2}\left(t_{0}\right)$ & $<0$ & & & \\
\hline$\vdots$ & $\vdots$ & & & \\
\hline$O_{34}\left(t_{0}\right)$ & $>0$ & & & \\
\hline$O_{1}\left(t_{1}\right)$ & $>0$ & $>0$ & $>0$ & $\begin{array}{l}\text { Effect-increasing transformation } \\
\text { of positive qualitative change }\end{array}$ \\
\hline$O_{2}\left(t_{1}\right)$ & $>0$ & $>0$ & $<0$ & Positive qualitative change \\
\hline$\vdots$ & $\vdots$ & $\vdots$ & $\vdots$ & $\vdots$ \\
\hline$O_{34}\left(t_{1}\right)$ & $>0$ & $>0$ & $>0$ & $\begin{array}{l}\text { Effect-increasing transformation } \\
\text { of positive qualitative change }\end{array}$ \\
\hline$O_{1}\left(t_{2}\right)$ & $>0$ & $>0$ & $>0$ & $\begin{array}{l}\text { Effect-increasing transformation } \\
\text { of positive qualitative change }\end{array}$ \\
\hline$O_{2}\left(t_{2}\right)$ & $>0$ & $>0$ & $<0$ & Positive qualitative change \\
\hline$\vdots$ & $\vdots$ & $\vdots$ & $\vdots$ & $\vdots$ \\
\hline$O_{34}\left(t_{2}\right)$ & $>0$ & $>0$ & $>0$ & $\begin{array}{l}\text { Effect-increasing transformation } \\
\text { of positive qualitative change }\end{array}$ \\
\hline$O_{1}\left(t_{3}\right)$ & $>0$ & $>0$ & $>0$ & $\begin{array}{l}\text { Effect-increasing transformation } \\
\text { of positive qualitative change }\end{array}$ \\
\hline$O_{2}\left(t_{3}\right)$ & $>0$ & $>0$ & $<0$ & Positive qualitative change \\
\hline$\vdots$ & $\vdots$ & $\vdots$ & $\vdots$ & $\begin{array}{l}\vdots \\
-\infty\end{array}$ \\
\hline$O_{34}\left(t_{3}\right)$ & $>0$ & $>0$ & $>0$ & $\begin{array}{l}\text { Effect-increasing transformation } \\
\text { of positive qualitative change }\end{array}$ \\
\hline
\end{tabular}

Table 6. Extension Classification of Conductive Information Elements in Terms of Teaching Workload $c_{g}$

\begin{tabular}{|c|c|c|c|c|}
\hline & $\boldsymbol{k}\left(v_{i 8}\right)$ & $\alpha\left(v_{i 8}\right)$ & $\beta\left(v_{i 8}\right)$ & Extension Classification \\
\hline$O_{1}\left(t_{0}\right)$ & $>0$ & & & \\
\hline $\mathrm{O}_{2}\left(t_{0}\right)$ & $>0$ & & & \\
\hline$\vdots$ & $\vdots$ & & & \\
\hline$O_{34}\left(t_{0}\right)$ & $>0$ & & & \\
\hline$O_{1}\left(t_{1}\right)$ & $>0$ & $>0$ & $>0$ & $\begin{array}{l}\text { Effect-increasing transformation of } \\
\text { positive qualitative change }\end{array}$ \\
\hline$O_{2}\left(t_{1}\right)$ & $>0$ & $<0$ & $>0$ & $\begin{array}{l}\text { Effect-decreasing transformation } \\
\text { of positive qualitative change }\end{array}$ \\
\hline$\vdots$ & $\vdots$ & $\vdots$ & $\vdots$ & $\vdots$ \\
\hline$O_{34}\left(t_{1}\right)$ & $>0$ & $>0$ & $>0$ & $\begin{array}{l}\text { Effect-increasing transformation of } \\
\text { positive qualitative change }\end{array}$ \\
\hline$O_{1}\left(t_{2}\right)$ & $>0$ & $<0$ & $>0$ & $\begin{array}{l}\text { Effect-decreasing transformation } \\
\text { of positive qualitative change }\end{array}$ \\
\hline$O_{2}\left(t_{2}\right)$ & $>0$ & $<0$ & $>0$ & $\begin{array}{l}\text { Effect-decreasing transformation } \\
\text { of positive qualitative change }\end{array}$ \\
\hline$\vdots$ & $\vdots$ & $\vdots$ & $\vdots$ & $\vdots$ \\
\hline$O_{34}\left(t_{2}\right)$ & $>0$ & $>0$ & $>0$ & $\begin{array}{l}\text { Effect-increasing transformation of } \\
\text { positive qualitative change }\end{array}$ \\
\hline$O_{1}\left(t_{a}\right)$ & $>0$ & $<0$ & $>0$ & $\begin{array}{l}\text { Effect-decreasing transformation } \\
\text { of positive qualitative change }\end{array}$ \\
\hline$O_{2}\left(t_{a}\right)$ & $>0$ & $<0$ & $>0$ & $\begin{array}{l}\text { Effect-decreasing transformation } \\
\text { of positive qualitative change }\end{array}$ \\
\hline$\vdots$ & $\vdots$ & $\vdots$ & $\vdots$ & $\vdots$ \\
\hline$O_{34}\left(t_{3}\right)$ & $>0$ & $<0$ & $>0$ & $\begin{array}{l}\text { Effect-decreasing transformation } \\
\text { of positive qualitative change }\end{array}$ \\
\hline
\end{tabular}




\subsubsection{Acquisition of Extension Classification Knowledge of Conductive Information Elements}

According to Table 5, there is extension classification knowledge as shown in Figure 1 in terms of the evaluation of feature research workload. Where, the number of conductive information elements is $|\{I\}|=102$, the number of elements in positive region before the transformation was conducted is $\| E_{+}[=75$, and the number of elements of correlation difference $\alpha_{i}>0$ in positive region after the transformation was conducted is $\left|E_{+}(\varphi)\right|=51$. Substitute them into the formula for calculation of the support and confidence of the positive quantification effect-increasing transformation, and we obtain:

$$
\ell_{c_{7}}=\text { (support, confidence) }=\left(\frac{\left|E_{+}\right|}{|\{I\}|} \frac{\left|E_{+}(\varphi)\right|}{\left|E_{+}\right|}\right)=\left(\frac{75}{102}, \frac{51}{75}\right)=(73.53 \%, 68.00 \%)
$$

This conductive knowledge indicates that the basic workload of 120 scores can be completed before the transformation of the teachers' research workload. After the scoring standard for research work was increased to 10 scores/month, the completion condition of the workload was further improved. At the same time, the support and confidence were respectively $73.53 \%$ and $68.00 \%$, and it was the most important and accurate knowledge among the seven items of extension classification knowledge about the evaluation feature research workload.

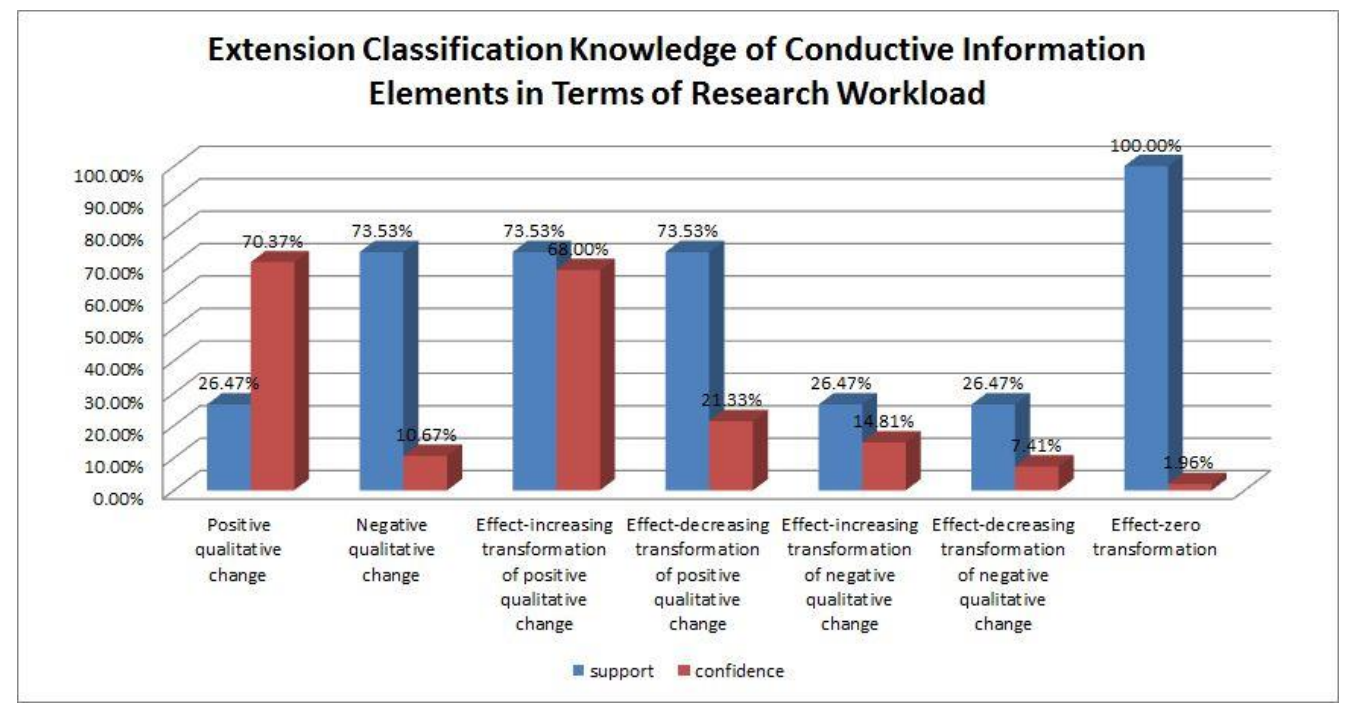

Figure 2. Extension Classification Knowledge of Conductive Information Elements in Terms of Research Workload

According to Table 6, there is extension classification knowledge as shown in Figure 2 in terms of the evaluation of feature teaching workload. Where, the number of conductive information elements is $|\{I\}|=102$, the number of elements in positive region before the transformation was conducted is $\| E_{+} \mid=87$, and the number of elements of correlation difference $\alpha_{i}<0$ in positive region after the transformation was conducted is $\left|E_{+}(\varphi)\right|=68$. Substitute them into the formula for calculation of the support and confidence of the positive quantification effect- decreasing transformation, and we obtain:

$$
\ell_{c_{\mathrm{g}}}=\text { (support, confidence) }=\left(\frac{\left|E_{+}\right|}{|\{I\}|} \frac{\left|E_{+}(\varphi)\right|}{\left|E_{+}\right|}\right)=\left(\frac{87}{102}, \frac{68}{87}\right)=(85.29 \%, 78.16 \%)
$$




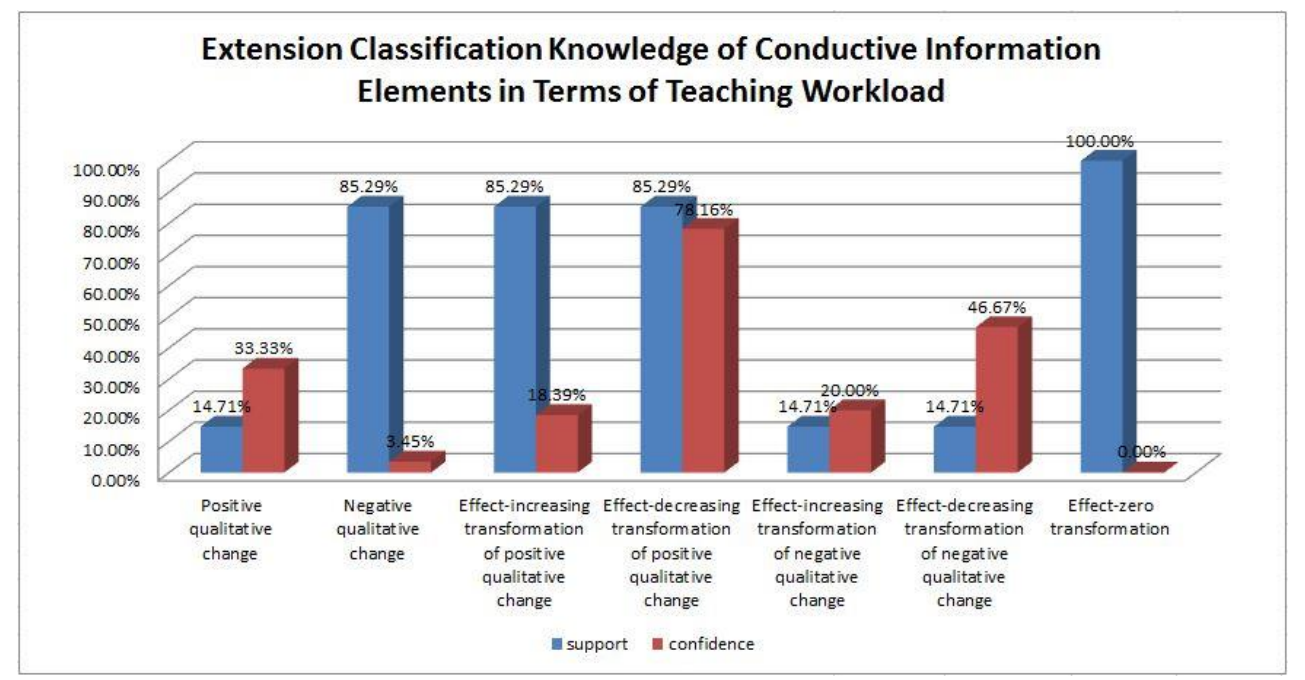

Figure 3. Extension Classification Knowledge of Conductive Information Elements in Terms of Teaching Workload

This conductive knowledge indicates that the basic workload of 320 scores can be completed before the transformation of the teachers' teaching workload. After the scoring standard for research work was increased to 10 scores/month, the completion condition of the teaching workload was reduced. At the same time, the support and confidence were respectively $85.29 \%$ and $78.16 \%$, and it was the most important and accurate knowledge among the seven items of extension classification knowledge about the evaluation feature research workload.

By integrating the above-mentioned conductivity knowledge and the extension classification knowledge obtained through the extension data mining technology, it can be concluded that the teachers' research workload was significantly improved after the score for the research was increased to 10 scores/month, but the teaching workload decreased to a certain extent, and the focus of teachers' work inclined to the scientific research.

\section{Conclusion}

In this paper, the conductive knowledge mining method is applied to the management of college teachers' workload. The conductive knowledge with high support and confidence is obtained, which can help the management departments of colleges and universities to learn that the effects of a strategy on teachers' workload are positive or negative, as well as the degree of effects, so that they can determine the most appropriate strategy to promote the enhancement of teachers' research. Through real case study results, it illustrates that the knowledge mined is helpful to adjust relevant control strategy. Next, we will conduct in-depth research on issues like the realization of the extension clustering knowledge mining ${ }^{[6]}$, extension knowledge mining on the basis of knowledge-base, as well as conductive knowledge mining system on computer, so as to make preparation for developing the strategy generation system ${ }^{[16][17]}$ based on the extension data mining.

\section{Acknowledgements}

The work described in this paper was supported by National Natural Science Foundation of China (No.61106019), also supported by Science and technology project of Guangdong Province (No: 2014A010103002), also supported by the exelementent young teachers program project of Guangdong Province(No:Yq2013201 and No:2015S02). 


\section{References}

[1] Jia Lijie, Yan Shuting and Zhu Qingxiang. Scientific Research Management System Based on the Quality Management System [J]. Chinese University Science \& Technology, 2011 (8): 24-25.

[2] Wang Xinyu. Research Management System Based on .Net Framework [J]. Computer Systems \& Applications, 2014, 23 (5): 48-53.

[3] Li Xiaomei. Extension Data Mining Based on Products Sales According to Change of CPI [J]. Mathematics in Practice and Theory, 2009, 39 (4): 178-183.

[4] Yang Chunyan and Cai Wen. Research Progress in Extension Data Mining [J]. Mathematics in Practice and Theory, 2009, (39) 4: 134-141.

[5] Wang Jianlin, Yang Yinsheng and Wang Xueling. Evaluation of Land Use in Yellow River Delta Based on Extension Data Mining [J]. Journal of Jilin University Engineering and Technology Edition, 2012 (1): 479-483.

[6] Li Zhong, Chen Xinfang, Yu Guoqing, Prediction Model of Yellow River Break-up Date Based on Extension Data Mining. [J]. Water Resources and Power, 2013, 31 (9): 1-3, 19.

[7] Fang Yaomei and He Wanpeng. Application of Extension Data Mining in Teaching Quality Evaluation of Higher Institution [J]. Mathematics in Practice and Theory, 2009 (4): 82-87.

[8] Li Xiaomei, Yang Chunyan and Li Weihua. Conductive Knowledge Mining Based on Stock Market Affected by Refined Oil Tax Reform [J]. Application Research of Computers, 2010, (27) 8: 2865-2868.

[9] Ye Guangzi and Li Weihua. Application of Extension Data Mining in Teachers' Scientific Research Evaluation [J]. Mathematics in Practice and Theory, 2015, 45 (12): 53-59.

[10] Zhu Lingli, Li Weihua and Li Xiaomei. Research on Extension Knowledge Mining Software for Customer Value [J]. Journal of Guangdong University of Technology, 2012, (29) 4: 7-13.

[11] Yang Chunyan and Cai Wen. Research on Acquisition of Extension Classification Knowledge Based on Extension Set [J]. Mathematics in Practice and Theory, 2008, (38) 16: 184-191.

[12] Ye Guangzi, Li Weihua and Li Shufei. Component-based Design and Realization of Extension Strategy Generation System [J]. CAAI Transactions on Intelligent Systems, 2010, 4 (4): 366-371.

[13] Li Weihua and Yang Chunyan. Development of Extension Strategy Generation Software Based on HowNet [J]. Science \& Technology Review, 2014, (32) 36: 32-36.

[14] Yang Chunyan, Li Xiaomei, Chen Wenwei Extension Data Mining Method and Its Computer Implement [M]. Beijing: Science Press, 2010.

[15] Yang Chunyan and Cai Wen. Extenics [M], Beijing: Science Press, 2014.

[16] Zhao Yanwei and Su Nan. Extension Design [M], Beijing: Science Press, 2010.

[17] Cai Wen, Yang Chunyan, Chen Wenwei, Extension Set and Extension Data Mining [M]. Beijing: Science Press, 2008.

\section{Authors}

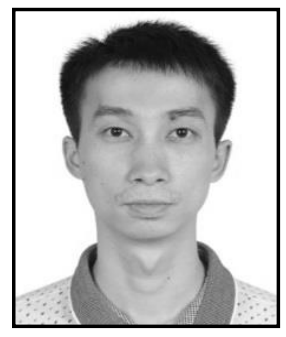

Ye Guangzi, Male, Born in 1981, Lecturer, Master, Research direction: Intelligent system software.

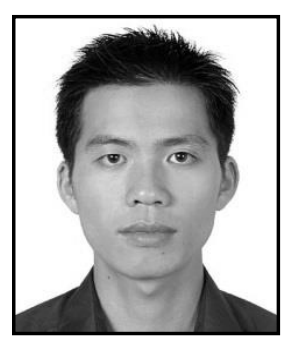

Chen Yuqiang, Male, Born in 1980, Professor, Doctor, Research direction: Automatic control and computer applications. 
International Journal of Database Theory and Application

Vol.10, No.1 (2017)

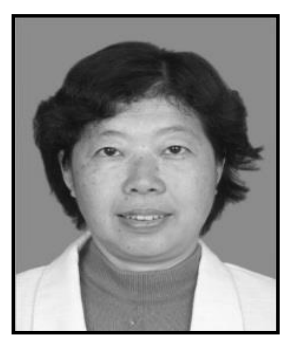

Li Weihua, Female, Born in 1957, Professor, Doctor, Research direction: Agent oriented computing、Intelligent system software. 